Çukurova Üniversitesi Mühendislik Mimarlık Fakültesi Dergisi, 32(4), ss. 201-210, Aralık 2017

\title{
Isınma Periyodu Belirleme Yöntemlerinin Etkinliklerinin Analizi
}

\author{
Nuşin UNCU ${ }^{* 1}$ \\ ${ }^{1}$ Adana Bilim ve Teknoloji Üniversitesi, Endüstri Mühendisliği Bölümü, Adana
}

Geliş tarihi: 07.06.2017～Kabul tarihi: 19.12.2017

\section{$\ddot{O} z$}

Kesikli olay simülasyonunda, performans çıktı değerlerinin yansız tahmini için sistemi başlangıç durumu etkilerinden arındırmak gerekmektedir. Özellikle sonlanmayan modellerde, sistemin durağan duruma ulaşana kadar geçirdiği süre yani 1sınma periyodu istatistikleri, performans çıktı değerlerinin üzerindeki yanlı etkilerinin ortadan kaldırılması için hesaplamalara dâhil edilmemelidir. Simülasyon ve optimizasyon yöntemlerinin birlikte kullanıldığı problemlerde ise simülasyon parametrelerinin her koşum öncesi güncellenmesi isınma periyodunda da değişimlere sebep olmaktadır. Bu değişimi azaltmak için, anlık 1sınma periyodu belirleme yöntemleri kullanılmaktadır. Bu çalışmada, Welch Grafik yöntemi ve anlık 1sınma periyodu belirleme yöntemlerinden Üstel Değişim Oranı Kuralı ve Öklid Uzaklığı yöntemleri M/M/1 kuyruk modeli için uygulanmıştır. Yöntemler etkinlikleri analitik sonuçlara yakınsama başarımları ve CPU zamanları bazında etkinlikleri karşılaştırılmıştır.

Anahtar Kelimeler: Simülasyon, Isınma periyodu, Welch grafiği, Öklid uzaklı̆̆ı, Üstel değişim oranı kural1, Lyapunov üssü

\section{Analyzing Effectiveness of Warm Up Detection Methods}

\begin{abstract}
In discrete event system simulation, it is necessary to purify the system from effects of its initial conditions for unbiased estimation of performance outputs. Particularly in non-terminating models, the period during which the system reaches the steady state, that is, the warm-up period statistics, should not be included in the calculations to remove the biased effects on the performance output values. In problems which simulation and optimization methods are used together, the update of simulation parameters before each run results in variation of warm up periods. In order to decrease this variation, the online warm up determination methods are used. In this study, Welch's Graphical method and two online warm up detection methods: Exponential Variation Rate Rule and Euclidean Distance methods are applied for $\mathrm{M} / \mathrm{M} / 1$ queueing systems simulation. The effectiveness of these methods based on convergence to the analytic solutions and CPU times are compared.
\end{abstract}

Keywords: Simulation, Warm up detection, Welch's graphical method, Euclidean distance, Exponential variation rate, Lyapunov exponent

"Sorumlu yazar (Corresponding author): Nuşin UNCU, nuncu@adanabtu.edu.tr 


\section{GíRiş}

Kesikli olay simülasyonlarında, sistemin durağan duruma ulaşıp ulaşmadığını tespit etmek önemli problemlerden biridir. Elde edilecek performans değerlerinin doğruluğu bu değerlerin yansız tahmin ediciler olmasına bağlıdır. Bu performans değerlerinin yansız olmaları için başlangıç koşullarından bağımsız hale getirilmiş olması gerekmektedir. Çünkü başlangıç koşullarında sistem durum değişkenleri $t=0$ anında sistemdeki müşteri sayısı $N(t)=0$ 'dır ve henüz sunucu uzun dönem yoğunluğuna ulaşmamıştır. Yani başlangıç koşulları, uzun dönem sistem durumunu ifade etmekten uzaktır. Sistemin başlangıç anından uzun dönem istatistiklerine ulaştığı ana kadar geçen süre, 1sınma periyodu, bu sebeplerden dolayı yapılacak hesaplamalara dâhil edilmemelidir. Yaygın olarak, 1sınma periyodu, klasik grafiksel yöntemler ya da yaklaşık süreler dikkate alınarak belirlense de doğru sürenin tespiti için birçok yöntem geliştirilmiştir. $\mathrm{Bu}$ yöntemler kullanıldıkları amaçlara göre farklı performanslar göstermektedirler. $\mathrm{Bu}$ performanslar isınma periyodunun alındığı süreye göre değişiklik arz eder. Isınma periyodunun çok kısa alındığı durumlarda, simülasyon performans değerleri yanlı olabileceği gibi; çok uzun alındığında ise veri kaybına ve durağan durum parametrelerinin tahminindeki güvenirliliğin azalmasına sebep olmaktadır. Sürenin tespitinin yanı sıra kullanılan yöntemlerin bazı özellikleri de bu yöntemlerin kullanılabilirliğini artıracaktır. $\mathrm{Bu}$ özellikler aşağıda verilmiştir.

i. Basitlik: Her kullanıcı için anlaşılabilir olmasi. Kompleks hesaplamalardan uzak olması ve rahatlıkla yorumlanabilir olması gerekmektedir.

ii. Uygulanabilirlik: Kolaylıkla uygulanabilir olmasi.

iii. Doğruluk: Isınma periyodunun tahmininde doğruluk.

iv. Yaygınlık: Özel durumlar için sınırlamalar olmaması ve genel kullanımının yaygın olmasi.

v. Etkinlik: Çok fazla sayıda parametre tahminine gerek duymamasi. Aksi takdirde etkinliği azalacaktır.
Simülasyon deneylerinden elde edilen sonuçların doğruluğun arttırılması için 1sınma periyodu belirleme yöntemlerinin hassasiyeti önemlidir. Özellikle son yıllarda sıklıkla kullanılan simülasyon optimizasyon yöntemlerinde isınma periyodunun tespiti sonuçların güvenilir ve doğru olması açısından daha büyük önem arz etmektedir. Çünkü değişen parametreler ve koşullar altında sistemin bir sonraki durum için tekrar durağan duruma gelmesi farklı isınma periyotlarının ele alınmasını gerektirir. Sonucun güvenirliliği ve uygulanabilirliği arasındaki ödünleşmeye kullanıcı karar vermelidir. $\mathrm{Bu}$ şekilde, çalışmanın bir sonraki bölümünde belirtilen isınma periyodu belirleme yöntemleri arasından doğru bir tercih yapılabilecektir.

$\mathrm{Bu}$ çalışmada klasik grafiksel yöntemlerden Welch yöntemi ve anlık isınma periyodu belirleme yöntemlerinden Üstel Değişim Oranı Kuralı ve Öklid Uzaklığı yöntemleri kullanılmıştır. Model olarak kuyruk modellerinden M/M/1 modeli analitik sonuçlarının da olması ve basitçe uygulanabilirliği açısından tercih edilmiştir. Isınma periyotları çıkarıldıktan sonra elde edilen performans çıktı değerlerinin analitik sonuçlara yakınsamalarının yanı sıra yöntemlerin CPU süreleri de karşılaştırılmıştır. Yöntemler, özellikleri anlamında da kullanım alanlarına göre de irdelenmiştir.

\section{2. ÖNCEKİ ÇALIŞMALAR}

Isınma periyodu ile ilişkili olarak literatürde 42 yöntem bulunmaktadır [1]. Çizelge 1'de bu alanda kullanılabilecek ve kullanılan bazı yöntemlere ve bu yöntemler ile ilgili referanslara yer verilmiştir. Yöntemler, grafiksel, sezgisel, istatistiksel ve hibrid yöntemler başlıkları altında gruplandırılarak incelenmiştir.

Grafiksel yöntemler, Welch metodu hariç ısınma periyodu belirlemek amacı dışında ortaya konulmuş yöntemlerdir. $\mathrm{Bu}$ yöntemler ile uygulayııı grafik üzerinde döktüğü performans çıktılarının grafiksel davranışlarından ısınma 
periyodunun süresinin kestirimini yapabilmektedir. Kullanıcı bağımlı yöntemlerdir. Sezgisel yöntemlerden, Üstel Değişim Oranı Kuralı kullanan Oh ve Park [2], bu yöntemi çoklu replikasyon gerektiren MSER5 metodunun performansı ile karşılaştırmışlardır. .Bu çalışma Lee ve arkadaşları [3]'nın çalışmalarındaki Lyapunov üssü kullanarak geliştirdikleri tersine simulasyon optimizasyon algoritmasıyla aynı temel felsefeye sahiptir. Her iki sezgisel de Lyapunov üssü kullanılarak ardı ardına gelen değişkenlerdeki birbirlerine göre meydana gelen ufak değişimleri kestirebilmek için geliştirilmiş algoritmalardır. Sezgisel yaklaşımlardan MSER ve MSER-5'in Yanlılık Tespit Testi, Yığın Ortalamas1 Testi, Maximum Testi ve Schruben'nin Alternatif Yöntemi karşılaştırılmış ve MSER-5 doğruluk açısından diğer yöntemlere göre başarılı bulunmuştur [4]. Robinson [5], istatistiksel süreç kontrol yönteminin grafiksel ve istatistiksel yöntemlerin bir hibridi olduğunu belirterek aralarında $\mathrm{M} / \mathrm{M} / 1$ modeli de olan yedi farklı model için uygulamıştır.

Diğer yöntemler ile ilgili referanslar Çizelge 1'de verilmiştir.

Çizelge 1. Isınma periyodu belirleme yöntemleri ve referanslar

\begin{tabular}{|c|c|}
\hline Metot & Referanslar \\
\hline \multicolumn{2}{|l|}{ Grafiksel Yöntemler } \\
\hline Zaman Serileri & {$[6]$} \\
\hline Topluluk Ortalaması Grafikleri & [7] \\
\hline Kümülatif Ortalama Kuralı & {$[6],[7],[8],[9],[10],[11],[12],[13],[14],[15]$} \\
\hline Kümülatif Ortalama Silme Kuralı & {$[11],[12]$} \\
\hline CUSUM Grafikleri & [10] \\
\hline Welch Yöntemi & {$[7],[14],[15],[16],[17],[18],[19],[20],[21]$} \\
\hline Varyans Grafikleri & {$[6],[8],[9],[17]$} \\
\hline İstatistiksel Süreç Kontrol Metodu & [19], [21] \\
\hline \multicolumn{2}{|l|}{ Sezgisel Yaklaşımlar } \\
\hline Conway Kuralı & {$[6],[8],[17],[21],[22],[23],[24],[25],[26],[27]$} \\
\hline Modifiye Edilmiş Conway Kuralı & {$[3],[8],[9],[27]$} \\
\hline Ortalamaların Kesişme Kuralı & {$[3][8],[9],[17],[24][27],[21]$} \\
\hline Otokorelasyon Tahmin Kuralı & {$[8],[17],[28]$,} \\
\hline MCR & {$[4],[15],[20],[21]$} \\
\hline MSER & [27] \\
\hline MSER-5 & [29] \\
\hline Yanlılık Tespit Testi & {$[10],[30],[31]$} \\
\hline Yı̆̆ın Ortalaması Testi & [31] \\
\hline Maximum Test & {$[31]$} \\
\hline Schruben'nin Alternatif Yöntemi & [32] \\
\hline Gevşeme Sezgiselleri & {$[11],[12],[17],[20][33]$} \\
\hline Sinir Ağları & [3] \\
\hline Öklid Uzaklığı & [3] \\
\hline Üstel Değişim Oranı Kuralı & {$[2]$} \\
\hline \multicolumn{2}{|l|}{ İstatistiksel Yöntemler } \\
\hline Uyum İyiliği Testi & [17] \\
\hline Kelton and Law Regresyon Yöntemi & {$[11],[12],[16],[17],[19],[20],[33],[34],[35]$} \\
\hline Rastgelelik Testi & {$[26],[21]$} \\
\hline \multicolumn{2}{|l|}{ Hibrid Yöntemler } \\
\hline Pawlikowski Ardışık Metodu & [17] \\
\hline $\begin{array}{l}\text { Değişmeyen Ölçek Yuvarlama Noktası metodu } \\
\text { İstatistiksel Süreç Kontrol Yaklaşımı }\end{array}$ & $\begin{array}{l}{[36]} \\
{[5]}\end{array}$ \\
\hline
\end{tabular}




\section{MATERYAL VE METOT}

\subsection{Materyal}

Kuyruk modellerinden $\mathrm{M} / \mathrm{M} / 1$ modeli test problemi olarak ele alınmıştır. M/M/1 kuyruk modelinde gelişler arası süreler ve servis süresi üstel dağılıma uyarken sistemde sadece bir adet servis sağlayıcı bulunmaktadır. M/M/1 modeli Şekil 1'de görülmektedir.

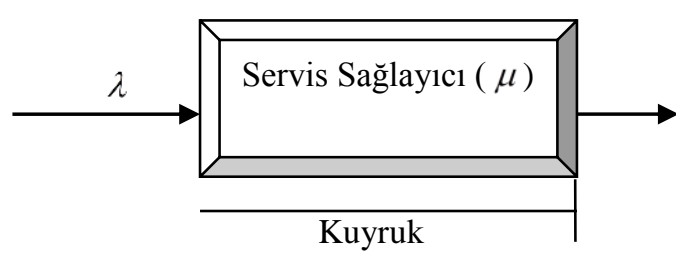

Şekil 1. M/M/1 kuyruk modeli

$\mathrm{Bu}$ modelin seçilmesinin en önemli sebebi performans değerlerinin analitik olarak elde edilebilmesi, dolayısıyla yöntemlerin performanslarının karşılaştııılmasında kolaylık sağlamasıdır. Bu çalışmada, gelişler arası ve işlem süreleri sırasıyla 30 ve 24 olarak alınmıştır.

\subsection{Metot}

\subsubsection{Welch Grafik Yöntemi}

Simülasyon modelleri 1sınma periyotlarının belirlemesi için kullanılan en basit yöntem grafik yöntemidir. Ancak, gözlemleyen kişinin belirlemesinden dolayı doğruluğu açısından her zaman iyi olduğunu söylemek mümkün değildir. Yine de kolay uygulanabilir bir yaklaşım olarak kabul edilebilir.

Welch Grafik Yönteminin adımları aşağıda sıralandığı gibidir $[19,34]$ :

- Simülasyon uzunluğu ' $m$ ' olan ' $n$ ' replikasyon çalıştırılır. m, yeterince büyük ve $n \geq 5$ olmalıdır.

$-Y_{j i}: j$. replikasyondaki $i$. gözlem $(j=1,2, \ldots$, $n ; i=1,2, \ldots, m)$ için her bir replikasyonda oluşan gözlemlerin ortalamaları
$\bar{Y}_{i}=\sum_{j=1}^{n} Y_{j i} / n, \quad i=1,2, \ldots, m$

ile hesaplanır.

- Replikasyon ortalamaları bulunduktan sonra, replikasyon ortalamalarındaki yüksek frekanslı dalgalanmaları azaltmak için düzgünleştirme yapılır. Hareketli ortalamaları $\bar{Y}_{i}(w)$ bulunur. Burada $w$ pencere değeridir ve pozitif tamsayıdır. $w \leq m / 4$ alınarak

$\overline{\mathrm{Y}}_{\mathrm{i}}(\mathrm{w})=\left\{\begin{array}{l}\frac{\sum_{\mathrm{s}-\mathrm{w}}^{\mathrm{w}} \overline{\mathrm{Y}}_{\mathrm{i}+\mathrm{s}}}{2 \mathrm{w}+1} \mathrm{i}=\mathrm{w}+1, \ldots, \mathrm{m}-\mathrm{w} \\ \frac{\sum_{\mathrm{s}-=(\mathrm{i}-1)}^{\mathrm{i}-1} \overline{\mathrm{Y}}_{\mathrm{i}+\mathrm{s}}}{2 \mathrm{i}-1} \quad \mathrm{i}=1, \ldots, \mathrm{w}\end{array}\right.$

ile hesaplanır.

$-\bar{Y}_{i}(w)$ değerlerini $i=1,2, \ldots ., m-w$ için grafik üzerinde yerleştir.

Grafik üzerinde, yatay eksen boyunca ilerleyen eğri düzgünleştirilmiş bir hal aldığında, eğrinin başlangıç noktasından azalarak artışı ve sonrasında yatay eksene paralel gittiği gözlenir. Simülasyoncu bu paralelliğin başladığı noktadan itibaren 1sinma periyodu kestirimini yapar. $w$ pencere değerleri ile beklenilen paralellik elde edilmediyse simülasyoncu daha fazla sayıda $m$ uzunlukta replikasyon yapmalıdır. Welch Grafik yöntemi birçok simülasyon deneyi yapmayı gerektirir. Dolayısıyla bu yöntemi isınma periyodunu anlık tespit etmek için kullanmak mümkün değildir. Aynı zamanda 1sınma periyodunun kestirimi kullanıcı bağımlı olduğu için yanlı olabilir.

\subsection{2. Üstel Değişim Oranı Kuralı Yöntemi}

Üstel Değişim Oranı Kuralı (Exponential Variation Rate Rule), sistemde değişkenliğin azaldığını tespit etmek amacıyla Lyapunov üssü mantığını kullanarak sonlandırma noktasının bulunmasını sağlayan bir yöntemdir [2]. Girdi parametreleri hakkında herhangi bir bilgi olmaksızın, bu yöntemle sistem dinamik karakterleri düzgün, kaotik ve rastgele hareketli olarak sınıflandırabilir. Üstel Değişim Oranı Kuralı ile çıktı serilerinin değişim oranlarına 
bakarak sonlandırma noktasına karar verilir (Şekil 2). Yöntem şu şekilde uygulanır;

Çıktı serileri $\{Y i: i=1,2, \ldots, n\}$ olsun.

Üstel değişim oranı;

$\lambda_{i}=\left|\log \frac{Y_{i+1}}{Y_{i}}\right|, \quad i=1,2, \ldots, n-1$

formülü ile hesaplanır. Sistem simülasyonu yapıldığında, performans çıktılarından elde edilen üstel değişim oranı $\lambda_{i}, 0,0356$ sayısından $300 \mathrm{kez}$ art arda küçük olmalıdır. $\mathrm{Bu} \lambda_{i}$ değerlerinin bir dağılıma uygun olarak yakınsadığını gösterir.

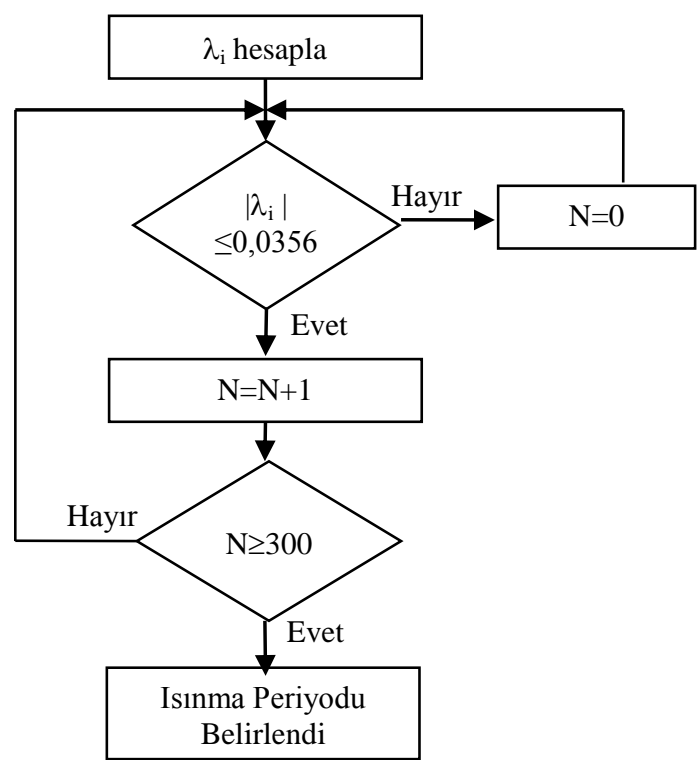

Şekil 2. Üstel değişim oranı kuralı yöntemi

\subsection{3. Öklid Uzaklığı Yöntemi}

M/M/1 modelinin 1sınma periyodunu belirlemek için uygulanan Öklid uzaklığı yönteminin aşamaları Şekil 3'de görülmektedir.

$\mathrm{Bu}$ yöntemde $x_{i}$ değerleri simülasyon performans çıktısı olan 10 boyutlu bir vektör ele alınmaktadır. Orijin ve vektör arasındaki Öklid uzaklığı; $d=\sqrt{x_{1}^{2}+x_{2}^{2}+\ldots+x_{10}^{2}}$

Her bir simülasyon çıktısının normalizasyonu için $f=1 / d$ faktörü bulunur. Her bir çıktı değeri bu faktörle çarpılarak normalize $\left(X^{\prime}\right)$ edilir. $X$ değerleri $[0,1]$ aralığında bulunmaktadır.

Lee ve arkadaşları [37] yaptıkları çalışmada kaynak kullanım oranını performans çıktı değeri olarak almışlar ve buna bağlı olarak en uygun ısınma periyodunu belirlemişlerdir. $\mathrm{Bu}$ yöntem ile her bir $x_{i}$ değeri 1 olarak alındığında elde edilecek $f$ değeri 0,316227766 olacaktır. Lee ve arkadaşları [37], $X^{\prime}$ değerlerinin 5 kez 0,3162276 ve 0,3162278 arasında olması durumunda durağan duruma ulaşıldığını söylemişlerdir.

Lee ve arkadaşları [37], çalışmalarında Öklid Uzaklığı yönteminin ısınma periyodunu uzun aldığını ve simülasyon süresi de buna bağlı olarak uzun tutulmazsa çok fazla veri silinmesine sebep olduğunu söylemişlerdir.

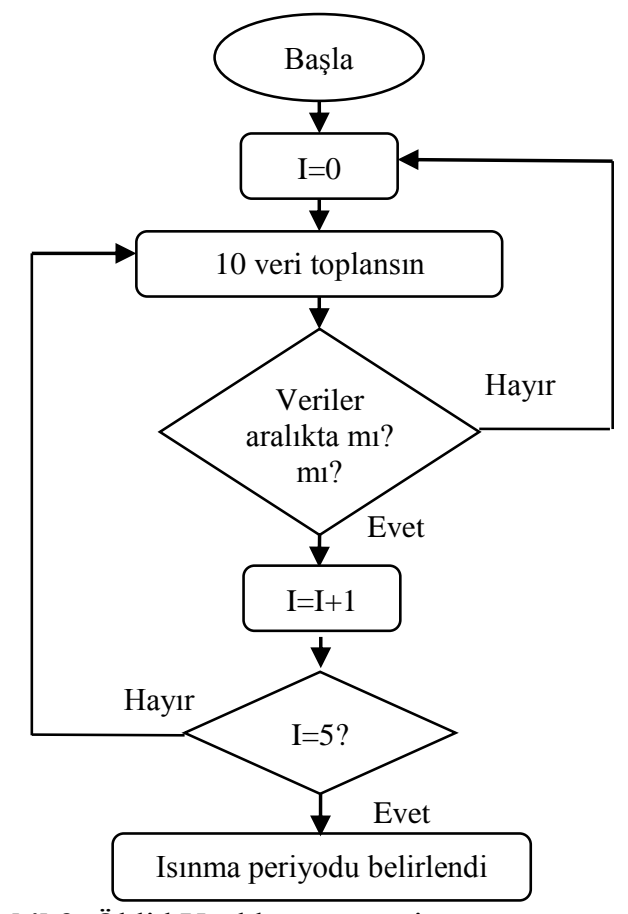

Şekil 3. Öklid Uzaklığı yöntemi 
Şekil 3'te görüldüğü gibi Öklid Uzaklığı yöntemi ile performans değişkeni olarak art arda kaydedilen 10 değerin istenilen aralıklara düşüp düşmediği kontrol edilir. Beklenen aralığa art arda 5 kez düşüp düşmediği kontrol edilerek düştüğü nokta isınma periyodu olarak belirlenir.

\section{BULGULAR}

Üç farklı 1sınma periyodu belirleme yöntemi için Arena 13,5 (Trial) programı ile M/M/1 modelleri oluşturulmuştur. Modeller Intel Core (TM) i5, 3,20 Ghz işlemci bilgisayar kullanılarak çalıştırılmıştır. Her yöntem için ısınma periyodu belirleme performans çıktısı kuyrukta ortalama bekleme süreleri $\left(\mathrm{W}_{q}\right)$ ve replikasyon sayısı 5 olarak alınmıştır.
Welch grafik yöntemi ile 1sınma periyodunun tespiti için M/M/1 modeli $300000 \mathrm{dk}$ çalıştırılmış, her bir müşterinin kuyrukta bekleme süreleri kaydedilmiştir. Ortalama kuyrukta bekleme sürelerinin değerlerinin düzgünleştirilmiş grafiği Şekil 4'de görülmektedir. Bu grafiğe göre yaklaşık olarak $10000 \mathrm{dk}$. sonrasında ortalama kuyrukta bekleme sürelerindeki değişimin bir durağanlık izlediği grafik üzerindeki kırmızı çizgiden görülmektedir. $\mathrm{Bu}$ süreden sonra herhangi bir zaman değeri ısınma periyodu olarak alınabilir. Ancak çok büyük bir zaman diliminin alınması ile çıktı performansını değerlendirmek için gerekli verilerin fazlası silinebileceğinden bu süre fark edilebilen ilk nokta olarak seçilmelidir. Aynı şekilde diğer yöntemler ile elde edilen grafikler incelenerek yöntemlerin isınma periyodunu tespitindeki hassasiyetleri incelenmiştir.

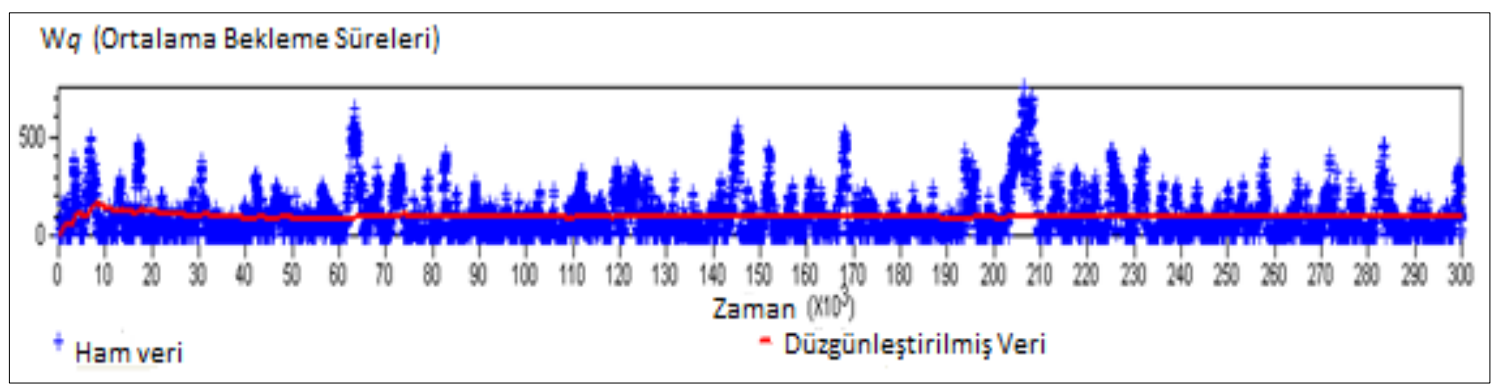

Şekil 4. Welch grafik yöntemi kullanıldığında simülasyon süresince ortalama kuyrukta bekleme sürelerinin hareketli ortalama grafiği

M/M/1 modeline Üstel Değișim Oranı Kuralı yöntemi uygulandığında yöntemin $12050 \mathrm{dk}$ sonra durağan duruma ulaşmış ve simülasyonu sonlandırmış olduğu görülmüştür. Şekil 5'te simülasyon süresi boyunca elde edilen ortalama kuyrukta bekleme sürelerinin düzgünleştirilmiş hareketli ortalama değerleri görülmektedir.

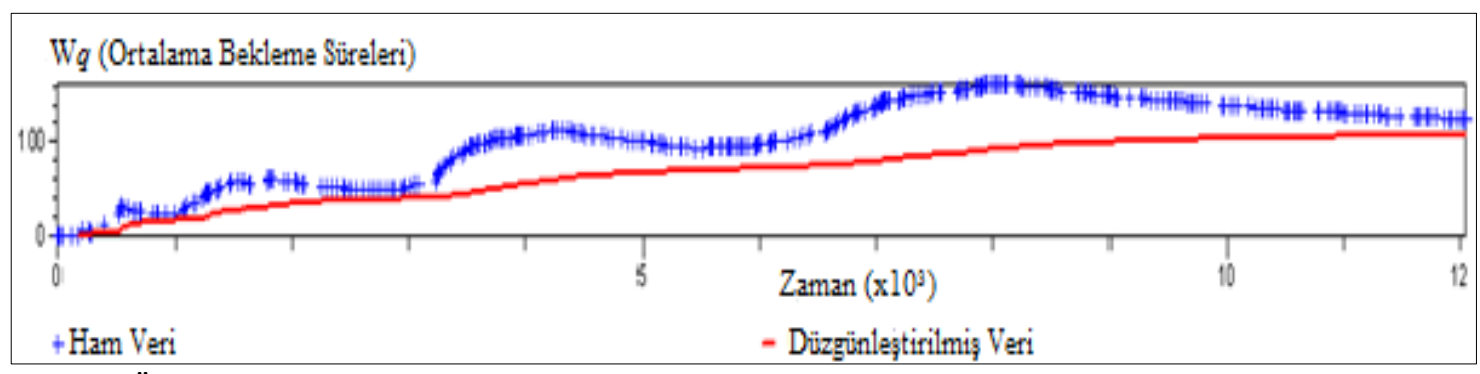

Şekil 5. Üstel değişim oranı kuralı yöntemi uygulandığında simülasyon süresince ortalama kuyrukta bekleme sürelerinin hareketli ortalama grafiği 
Öklid Uzaklığı yöntemi ile $X^{\prime}$ değerlerinin 5 kez art arda istenilen aralıklarda olması 6960502 dakika gibi çok uzun bir süre almıştır. Şekil 6'da görüldüğü gibi kırmızı çizginin düzgün bir şekilde ilerlemeye başladığı noktaya bakıldığında yöntemin sistemin durdurulduğu andan çok daha öncesinde durağan duruma ulaştığı görülüyor. Oysa Öklid Uzaklığı yöntemi daha uzun zaman sonra sistemin durağan duruma ulaştığını tespit etmiş ileri bir zamanda simülasyonu sonlandırmıştır. $\mathrm{Bu}$ da düşük hassasiyette bir yöntem olduğunu göstermektedir.

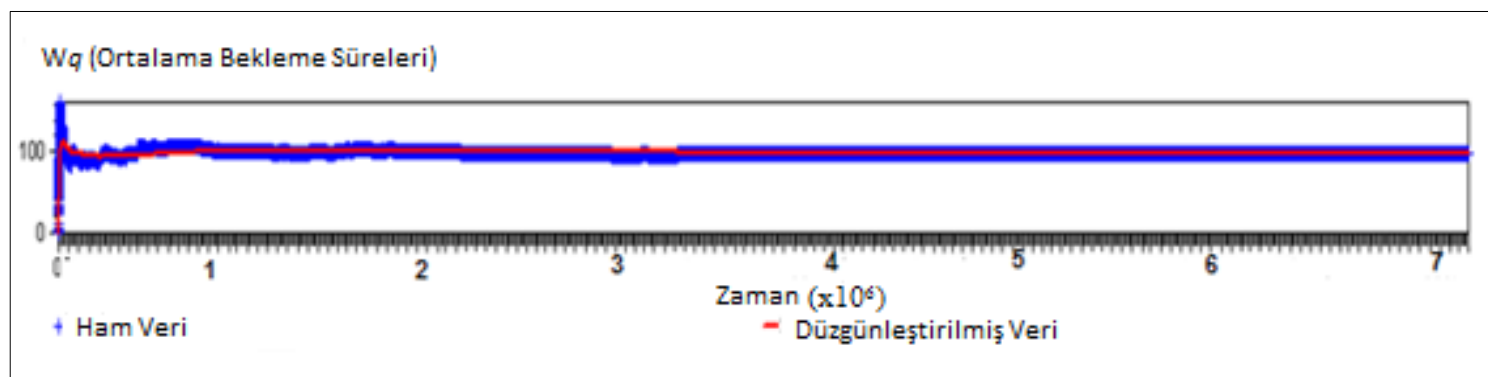

Şekil 6. Öklid Uzaklığı yöntemi uygulandığında simülasyon süresince ortalama kuyrukta bekleme sürelerinin hareketli ortalama grafiği

Anında ısınma periyodu belirleme yöntemleri 1sınma periyodunu belirledikten sonra simülasyonu durdurmuşlardır. Bu yöntemlerle performans çıktı değerlerine ulaşabilmek için Çizelge 2'de verildiği gibi yöntemlerin belirlediği ısınma periyotlarının 20 katı süre için simülasyon deneyleri tekrarlanmış ve performans çıktıları bu şekilde tespit edilmiştir.

Çizelge 2. Yöntemler bazında simülasyon ve 1sınma periyodu süreleri

\begin{tabular}{|l|l|l|l|}
\hline & \multicolumn{3}{|c|}{ Yöntem } \\
\hline & Welch & $\begin{array}{l}\text { Üstel } \\
\text { Değişim } \\
\text { Oranı }\end{array}$ & $\begin{array}{l}\text { Öklid } \\
\text { Uzaklığı }\end{array}$ \\
\hline $\begin{array}{l}\text { Simülasyon } \\
\text { süresi (dk) }\end{array}$ & 200000 & 241000 & 139210040 \\
\hline $\begin{array}{l}\text { Isınma } \\
\text { Periyodu } \\
(\boldsymbol{d} \text { k })\end{array}$ & 10000 & 12050 & 6960502 \\
\hline
\end{tabular}

Çizelge 3'te $\mathrm{M} / \mathrm{M} / 1$ kuyruk sistemine ait bazı durağan durum istatistikleri verilmiştir. Bunlar $W_{q}$ (kuyrukta ortalama bekleme süreleri), $W$ (sistemde ortalama kalma süreleri), $L_{q}$ (kuyrukta ortalama müşteri sayısı) ve $L$ (sistemdeki ortalama müşteri sayısı)'dir. Çizelge 3'te yöntemler kullanılarak elde edilen performans çıktı değerleri ile modelin analitik sonuçları ve bilgisayar işlem (CPU) süreleri verilmiştir. Üstel Değişim Oranı Kuralı ile elde edilen değerlerin diğer yöntemlere göre analitik sonuçlara yakınsama açısından daha başarılı olduğu görülmektedir. CPU sürelerine bakıldığında, Welch grafik yöntemi en hızlı, Öklid Uzaklığı yöntemi ise en uzun CPU süresi gerektirmiştir. $\mathrm{Bu}$ durum simülasyon süreleri ile doğru orantılı olsa da simülasyon sürelerinin de ısınma periyotlarının belirlenme süresine bağlı olarak uzadığ göz ardı edilmemelidir.

Çizelge 3. Yöntemlerden elde edilen sonuçlar ve CPU süreleri

\begin{tabular}{|l|c|c|c|c|}
\hline \multicolumn{2}{|l|}{} & \multicolumn{3}{|c|}{ Yöntem } \\
\hline $\begin{array}{l}\text { Performans } \\
\text { Çıktıları }\end{array}$ & $\begin{array}{c}\text { Analitik } \\
\text { Sonuç }\end{array}$ & Welch & $\begin{array}{c}\text { Üstel } \\
\text { Değişim } \\
\text { Oranı }\end{array}$ & $\begin{array}{c}\text { Öklid } \\
\text { Uzaklığı }\end{array}$ \\
\hline $\mathbf{W}_{\mathbf{q}}(d k)$ & 96 & 95,77 & $\mathbf{9 6 , 0 2}$ & 95,80 \\
\hline $\mathbf{W}(d k)$ & 120 & 119,76 & $\mathbf{1 2 0 , 0 1}$ & 119,80 \\
\hline $\mathbf{L}_{\mathbf{q}}$ & 3,2 & 3,17 & 3,18 & $\mathbf{3 , 2}$ \\
\hline $\mathbf{L}$ & 4 & 3,992 & $\mathbf{4}$ & 3,993 \\
\hline $\begin{array}{l}\text { CPU } \\
\text { süreleri } \\
(s n)\end{array}$ & - & $\mathbf{1 5}$ & 20 & 435 \\
\hline
\end{tabular}




\section{TARTIŞMA VE SONUÇ}

Simülasyon deneylerinde elde edilen sonuçların doğruluğunu arttırmak ve özellikle de son yıllarda simülasyon optimizasyon yöntemlerinin birlikte kullanıldığı düşünüldüğünde daha da önemli hale gelmiştir. Isınma periyodu belirleme yöntemlerinin etkinliği bu tür çalışmalarda elde edilen çıktının kalitesini arttıracak yanlılığını azaltacaktır. Bu çalışmada grafiksel, sezgisel, istatistiksel ve hibrid ısınma periyodu belirleme yöntemleri genel olarak incelenmiştir. $\mathrm{Bu}$ yöntemlerden birçoğu nihai simülasyon modelinden önce ön çalı̧̧ma yapılmasını gerektirmektedir. Anında 1sınma periyodu belirleme yöntemlerinin simülasyon deneyleri yapılırken 1sinma periyodu belirliyor olması etkin bir özelliktir. $\mathrm{Bu}$ çalışmada, literatürde de vurgu yapılan anında isınma periyodu belirleme yöntemlerinden iki tanesi ele alınmış ve grafiksel yöntemlerden olan Welch Grafik metodu sonuçları karşılaş̧ııılmışı̧ı. Welch grafik yöntemi kullanmak, kullanıcı bağımlı olması dolayısıyla hassasiyeti düşük bir yöntem olmakla birlikte analitik sonuçlara diğer yöntemlere göre daha uzak sonuçlar elde edilmesine sebep olmuştur. Öklid uzaklığı ve Üstel Değişim Oranı Kuralı yönteminin uygulanabilirliği aynı zorluktadır fakat simülasyon deneylerinin uzun sürmesi istenmediğinden özelikle simülasyon optimizasyon çalışmalarında Üstel Değişim Oranı Kuralı yöntemi kullanım açısından daha avantajlıdır. Üstel Değişim Oranı Kuralı yönteminin uygulanabilirlik, kolaylık ve doğruluk anlamında iyi bir yöntem olduğu söylenebilir.

Yapılan çalışmada görülmüştür ki anlık ısınma periyodu belirlenirken dikkate alınması gereken önemli kriterler vardır. Bunlar;

- Yöntemin 1sınma periyodunu uzun alarak doğru istatistiklere ulaşmak için gerekli olan verilerin kaybına yol açmaması

- Yeterli uzunlukta alınmayan isınma periyodu sebebiyle yanlı sonuçlar elde edilmesinden kaçınılması

- Kullanılan yöntemin algoritmasının basit ve uygulanabilirliğinin kolay olması
- Çözüm süresinin uzun olmaması

Isınma periyodunun uzunluğu simülasyon süresinin uzunluğunu da etkilediği için bir sonraki çalışmada simülasyon süresi ve isınma periyodu arasındaki optimum ilişkinin açığa çıkarılması önerilebilir.

\section{TEŞEKKÜR}

Bu çalışma Adana Bilim ve Teknoloji Üniversitesi Bilimsel Araştırma Projeleri Birimi tarafindan desteklenmiştir. Proje No: 17103008.

\section{KAYNAKLAR}

1. Hoad, K., Robinson, S., Davies, R., 2008. Automating Warm-Up Length Estimation. Proceedings of Winter Simulation Conference, 532-540.

2. Oh, H., Park, K., 2006. An Effective Heuristic To Detect Warm-Up Period in Simulation Output. Proceedings of The Winter Simulation Conference, 182-188.

3. Lee, Y.H., Kyung, K-H., Jung, C-S., 1997. OnLine Determination of Steady State in Simulation Outputs, Computers\& Industrial Engineering, 33, 805-808.

4. White, K.P., Jr., Cobb, M.J., Spratt, S., 2000. Comparison of Five Steady-State Truncation Heuristics for Simulation. Proceedings of the Winter Simulation Conference, 755-760.

5. Robinson, S., 2007. A Statistical Process Control Approach to Selecting A Warm-Up Period for A Discrete-Event Simulation. European Journal of Operational Research, 176, 332-346.

6. Gordon, G., 1969. System Simulation. New Jersey: Prentice- Hall.

7. Banks, J., Carson, J.S., Nelson, B.L., Nicol D.M., 2001. Discrete-Event System Simulation, $3^{\text {rd }}$ Ed. Prentice Hall, Upper Saddle River, NJ.

8. Wilson, J.R., Pritsker, A.A.B., 1978a. A Survey of Research on the Simulation Startup Problem, 31:55-58.

9. Gafarian, A.V., Ancker, C.J., Morisaku, T., 1978. Evaluation of Commonly used Rules for Detecting 'Steady State' in Computer 
Simulation. Naval Research Logistics Quarterly, 25: 511-529.

10. Nelson, B.L., 1992. Initial-Condition Bias. In Handbook of Industrial Engineering, $2^{\text {nd }}$ Ed., Ed., G. Salvendy. Newyork: John Wiley.

11. Roth, E., Josephy, N., 1993. A Relaxation Time Heuristic for Exponential-Erlang Queueing Systems. Computers \& Operations Research 20(3): 293-301.

12. Roth, E., 1994. The Relaxation Time Heuristic for the Initial Transient Problem in $M / M / K$ Queueing Systems. European Journal of Operational Research. 72: 376-386.

13. Fishman, G.S., 2001. Discrete-Event Simulation, Modeling, Programming, and Analysis. New York: Springer- Verlag.

14. Bause, F., Eickhoff, M., 2003. Truncation Point Estimation using Multiple Replications in Parallel. In Proceedings of the 2003 Winter Simulation Conference, 414-421.

15. Sandıkçı, B., Sabuncuoğlu, İ., 2006. Analysis of the Behavior of the Transient Period in NonTerminating Simulations. European Journal of Operational Research, 173;252-267.

16. Law, A.M., 1983. Statistical Analysis of Simulation Output Data. Operations Research 31: 983-1029.

17. Pawlikowski, K., 1990, Steady-State Simulation of Queueing Processes: A Survey of Problems and Solutions. Computing Surveys, 22: $123-170$.

18. Alexopoulos, C., Seilai, A.F., 1998. Output Data Analysis, Handbook of Simulation, 225-272. New York: Wiley.

19. Law, A.M., Kelton, W.D., 2000. Simulation Modeling and Analysis, $3^{\text {rd }}$ Ed. New York: Mcgraw-Hill.

20. Linton, J.R., Harmonosky, C.M., 2002. A Comparison of Selective Initialization Bias Elimination Methods. In Proceedings of the Winter Simulation Conference, 1951-1957.

21. Mahajan P.S., Ingalls R.G., 2004, Evaluation of Methods used to Detect Warm-Up Period In Steady State Simulation. Proceedings of Winter Simulation Conference.

22. Conway, R.W., 1963. Some Tactical Problems in Digital Simulation. Management Science 10(1): 47-61.
23. Fishman, G.S., 1973. Concepts and Methods in Discrete Event Digital Simulation. New York: Wiley.

24. Wilson, J.R., Pritsker, A.A.B., 1978 b. Evaluation of Startup Policies in Simulation Experiments. Simulation 31(3): 79-89.

25. Bratley, P., B. Fox, Schrage, L., 1987. A Guide to Simulation, $2^{\text {nd }}$ Ed. New York: SpringerVerlag.

26. Yücesan, E., 1993, Randomization Tests for Initialization Bias in Simulation Output. Naval Research Logistics, 40: 643-663.

27. White, K.P., Jr. 1997. An Effective Truncation Heuristic for Bias Reduction in Simulation Output. Simulation, 69(6): 323-334.

28. Fishman, G.S., 1971. Estimating Sample Size in Computing Simulation Experiments Management Science 18: 21-38.

29. Spratt, S.C., 1998. Heuristics for the Startup Problem. M.S.Thesis, Department of Systems Engineering, University of Virginia.

30. Cash, C.R., Dippold, D.G., Long, J.M., Nelson, B.L., Pollard, W.P., 1992. Evaluation of Tests for Initial Conditions Bias. In Proceedings of the 1992 Winter Simulation Conference,

31. Goldsman, D., Schruben, L.W. Swain, J.J., 1994. Tests for Transient Means in Simulated Time Series. Naval Research Logistics, 41:171-187.

32. Schruben, L.W., 1982. Detecting Initialization Bias in Simulation Output. Operations Research, 30(3):151-153.

33. Kimbler, D.L., Knight, B.D., 1987. A Survey of Current Methods for the Elimination of Initialisation Bias in Digital Simulation. Annual Simulation Symposium 20: 133-142.

34. Kelton, W.D., Law, A.M., 1983. A New Approach for Dealing with The Startup Problem in Discrete Event Simulation. Naval Research Logistics Quarterly. 30:641-658.

35. Gallagher, M.A., Bauer Jnr, K.W., Maybeck, P. S., 1996. Initial Data Truncation for Univariate Output of Discrete-Event Simulations using the Kalman Filter. Management Science 42(4): 559-575.

36. Jackway, P.T., Desilva, B.M., 1992, A Methodology for Initialisation Bias Reduction in Computer Simulation Output. Asia-Pacific Journal of Operational Research, 9: 87-100. 
Isınma Periyodu Belirleme Yöntemlerinin Etkinliklerinin Analizi

37. Lee, Y.H., Kim, Y.B., Park, K.J., 1997. Single Run Optimization using Reverse Simulation Method. Proceedings of the WSC, 183-193. 